\title{
Some Considerations on the Activity of Insurance Business and its Relevance for a General Reassessment of Economic Theory : A Comment
}

\author{
by Peter J. Franklin *
}

Possibly the most universal feature of micro- and macro-economic theory is the use of the concept of optimum. This concept has several nuances : inter alia, the concept may be considered to be a normative feature; alternatively the state of the world described by an optimum may be no more than an ideal against which it is possible to compare and measure positions of disequilibria ; sometimes it may describe a relationship between only two variables, as in partial equilibrium theory, whereas at other times the optimum may be supposed to exist for a much larger number of variables, as in general equilibrium theory.

Whatever the nuance, we know it to be important not to confuse the optimum in theory with the "optimum" in reality. 1 Whereas the conditions which underlie an optimum which exists in theory can be described precisely using assumptions which limit or insulate the effects of other variables, including time, risk and information, the idea of an optimum in reality is difficult to grasp when there may be little or no information to judge whether the present state of the world can be considered to be "optimum".

The debate which still persists about profit maximisation is a good example of the difference between a theoretical notion and its empirical counterpart. ${ }^{2}$. In theory maximum profits can be described exactly as being the point where marginal revenue equals marginal cost : any state of the world where marginal revenue is less than or greater than marginal cost describes a non-optimal situation. By comparison, where in reality marginal magnitudes are unknown or imprecisely known, it is difficult to say whether any current level of total profit could be improved upon. ${ }^{3}$ In any case, the

* Director, Centre for Insurance Research, City of London Polytechnic.

1 Fritz Machlup [1967] wrote about misplaced concreteness in regards to the theory of the firm.

2 For an important contribution to that debate, see Loasby [1971]. On empirical counterparts, see Friedman [1953].

3 Machlup [1967] puts all this much more eloquently and fully. 
constraints under which real firms work - time, risk, imperfect information, labour disputes, competition, flexible exchange rates and government policy - cannot be merely assumed away in the catch-all ceteris paribus method to which theoretical economists are devoted and indebted.

Despite the obvious abyss between theory and reality, as economists we continue to operate unreal models and non-operational concepts. I suspect we do this for purely selfish reasons. Our culture prefers order rather than chaos, ${ }^{4}$ and as Shackle [1967] has pointed out, the very existence of a theory absolves us "from the tiresome labour of thought ". Furthermore, the use of the concepts of "optimum " and "equilibrium " in economic theory, have enabled economists to supply seemingly accurate deterministic answers - they have avoided having to admit that they do not know, or are uncertain as to the theoretical consequences of a theoretical action. ${ }^{5}$

This search to provide deterministic equilibrium solutions has led theoretical and applied economists to measure the unmeasurable. The theory of value, for example, is a case which typifies the former. Here utility is used to gauge the level of satisfaction an individual obtains from the consumption (?) of goods, while his utility is related to the market-determined price which he has to pay for the goods he consumes. Similarly, the construction of cost-benefit-analysis by applied economists has enabled the latter to pretend to be able to measure intangibles, like speed and comfort and the social costs of pollution - intangibles which do not have ready reference values given by the market place.

Going to the heart of the matter, Orio Giarini considers that the use of marketdetermined prices as denoting "value" is the key to the failure of economics to recognise insurance as a wealth producing activity. Quoting freely from various sources,

" if priced values are the key to economic analysis, then economics will center almost exclusively on monetarized production and consumption systems ". (Giarini, [1981], p. 87)

At least three important interrelated consequences follow from this proposition. First, free or "non monetarized" products have somehow to be included within the compass of economic theory (Giarini [1980], p. 29). Secondly, activities like insurance are seen as adding little to society's wealth, whereas in practice the "real value of insurance" is "the increase in wealth brought by the possibility of controlling probable damages" (Giarini [1981], p. 88). Thirdly, it is necessary to

"propose a new economics which is utterly post-industrial and where any kind of activity, provided it helps in developing welfare, is value productive, regardless if it fits or not in the traditional notion of added value. In this perspective insurance activities are eligible as wealth producing activities as any other industrial or secondary production." (Letter to the author, 16 June 1980.)

4 See Franklin [August 1979].

5 The behavioural theories of the firm show the difficulties of non-equilibrium analysis. 
If a "new economics" is to be proposed then it is obviously necessary to redefine our understanding and measure of economic value. Orio Giarini's concept of "utilization value" does just this. ${ }^{6}$ Furthermore his concept has for me the advantage of measuring value in a dynamic way, so that (for instance) any service or investment which extends the working life of a consumption good like a motor car, increases its utilization value and hence the wealth of society.

In a different way I have independently reached similar (not identical) propositions. Working on the fringes of our value paradigm it is clear that a theory like that of demand, which assumes goods to possess defined and certain characteristics, explicitly ignores the fact that consumption takes place over time. In the case of a washing machine, for example, if its performance is one of the most important characteristics determining consumer choice, then it would be important to recognise that the expected future life and number of break-downs of the machine would be affected by such matters as the frequency and heaviness of the wash, the type of water supply, and the frequency of maintenance and care. Indeed, summarizing some earlier work, the demand and supply of goods takes account of the fact that consumption takes place over time. Producers supply goods with guarantees concerning their technical properties and performance; the guarantees, I suspect, act as a form of insurance, and thereby comfort potential consumers so that their expected utility may be increased.

Giarini's approach and mine have therefore differed greatly. Visualising economic theory as some sort of orb, Giarini has gone right back to the centre to see where economics went wrong. ${ }^{7}$ His dissatisfaction with the way insurance is accounted for within National Income accounts has inevitably led him back to the theory of value. By comparison my own approach has been to stretch one or two ideas found in the theory of consumer behaviour ${ }^{8}$ so that uncertainty and insurance could be incorporated, so to speak, within the traditional value paradigm. Orio Giarini has therefore gone a long way towards satisfying his ambition of creating a "new economics". There is clearly still a long way to go, and anyone wishing to see some of the route - some of the signposts which have to be passed - should read his Dialogue. In any case I hope that others will pursue his "evaluations and hypotheses", and to that end would hope that a more formal Scientific Research Programme will be established to move our discipline beyond the seventeenth century. ${ }^{9}$

6 See Giarini [1980], p. 25 ff ; Chapter 2 passim, especially p. 121 ff.

7 See Kaldor [1972] for a view which is partly sympathetic to Giarini's.

8 See Franklin [January 1979] and Franklin and Woodhead [1980]. Unpublished papers [1976] and [August 1979] also explore the territory.

9 E. H. Phelps Brown, in a paper given to the Royal Economic Society, concludes that economic "science has hardly yet reached its 17 th century. I believe we shall make better progress when we realise how far we still have to go" [1972], p. 10. 


\section{REFERENCES}

FRANKLIN, P. J. [1976] : “Crisis and underdevelopment in industrial economics", unpublished working paper, September 1976.

FRANKLIN, P. J. [1979]: "The characteristics approach and its application to financial liabilities, financial assets and portfolio choice", The Geneva Papers on Risk and Insurance, 11 (January 1979), 52-62.

FRANKLIN, P.J. [1979] : “On uncertainty and insurance in economics", unpublished working paper, August 1979.

FRANKLIN, P. J., and WOODHEAD, C. [1980] : The UK Life Assurance Industry, Croom Helm, London.

FRIEDMAN, M. [1953] : "The methodology of positive economics", in Essays in Positive Economics, University of Chicago Press, 3-43.

GIARINI, O. [1980] : Dialogue on Wealth and Welfare, Pergamon Press, Oxford.

GIARINI, O. [1981] : "Some considerations on the activity of insurance business and its relevance for a general reassessment of economic theory", The Geneva Papers on Risk and Insurance, 21 (October 1981), 84-103.

KALDOR, N. [1972] : “The irrelevance of equilibrium economics", The Economic Journal, 82 (December 1972), 1237-1255.

LOASBY, B. J. [1971] : "Hypothesis and paradigm in the theory of the firm", The Economic Journal, 81 (December 1971), 863-885.

MACHLUP, F. [1967] : "Theories of the firm: Marginalist, behavioral, managerial", The American Economic Review, 57 (March 1967), 1-33.

PHELPS BROWN, E.H. [1972] : “The underdevelopment of economics", The Economic Journal, 82 (March 1972), 1-10.

SCHACKLE, G. L. S. [1967] : The Years of High Theory, Cambridge University Press. 


\title{
8th SEMINAR OF THE EUROPEAN GROUP OF RISK AND INSURANCE ECONOMISTS
}

September 23-25, 1981

\author{
UNIVERSITY OF COLOGNE \\ Institut für Versicherungswissenschaft \\ (Institute for Insurance Science) \\ Kerpenerstrasse 30 \\ Cologne (Germany)
}

\section{PROGRAMME}

WEDNESDAY, September 23

2.30 - 3.30 p.m. - Welcoming address by Prof. Dr. Dieter FARNY, Director of the Institute for Insurance Science.

- Opening address by the Chairman, Dr. Fabio PADOA.

- Round-table.

3.30 - 4.00 p.m. The Future of Capitalization in France

by Denis KESSLER and Dominique STRAUSS-KAHN (University of Paris-Nanterre).

4.00 - 4.30 p.m. Discussion.

5.00 - 5.30 p.m. Optimum Retirement Age

by Norma LARSEN and August RALSTON (University of Southern California).

5.30 - 6.00 p.m. Discussion (Discussant : Richard HEMMING, Institute for Fiscal Studies, London). 
THURSDAY, September 24

Morning session Moderator: Dieter FARNY (University of Cologne).

9.00 - 9.30 a.m. Insurance Capacity Cycles

by Neil DOHERTY (University of Alberta).

9.30 - 10.00 a.m. Discussion (Discussant: Gerry DICKINSON, City University Business School, London).

10.00 - 10.30 a.m. Inflation in the Health Care Sector and the Demand for Insurance: A Micro Study

by Peter ZWEIFEL (University of Zurich).

10.30 - 11.00 a.m. Discussion (Discussant : Karl BORCH, Norwegian School of Economics, Bergen).

11.30 - 12.00 a.m. A Comparison of Attitudes Towards Risk Among Business Managers

by Gordon DICKSON (Glasgow College of Technology).

12.00 - 12.30 p.m. Discussion (Discussant : Robert CARTER, University of Nottingham).

Afternoon session Moderator: Matthias HALLER (St. Gall Graduate School of Economics, Business and Public Administration).

2.30 - 3.00 p.m. Empirical Goal Research in Insurance Companies by Bernd KALUZA (University of Mannheim).

3.00 - 3.30 p.m. Discussion (Discussant : Giovanna FERRARA, Unioras, Rome).

3.30 - 4.00 p.m. Instruction in Insurance in Canadian Universities by Jean-François OUTREVILLE (Laval University).

Workshop A Statistics for Research in Risk and Insurance.

Moderator : Robert CARTER (University of Nottingham).

Workshop B Academic Instruction in Risk and Insurance.

Moderator : Henri LOUBERGE (Geneva Association).

Workshop C Insurance Economics and the Nationalization of the Insurance Industry.

Moderator : Orio GIARINI (Geneva Association). 
FRIDAY, September 25

Moderator : Walter KARTEN (University of Hamburg).

9.00 - 9.30 a.m. Competition and Regulation in Insurance by Roland EISEN (University of Munich-Weihenstephan).

9.30 - 10.00 a.m. Discussion (Discussant : Leigh ROBERTS, City University Business School, London).

10.00 - 10.30 a.m. Competition and Cooperation in Insurance by Peter FRANKLIN (City of London Polytechnic).

10.30 - 11.00 a.m. Discussion (Discussant : Lawrence GALITZ, University College of North Wales, Bangor).

11.30-12.00 a.m. Returns to Scale in the Swedish Property-Liability Insurance Industry

by Göran SKOGH (University of Lund).

12.00 - 12.30 p.m. Discussion (Discussant : Louis EECKHOUDT, Laval University). 